\title{
Predictions of Crowdfunding Campaign Success: The Influence of First Impressions on Accuracy and Positivity
}

\author{
Etienne Schraven, Elco van Burg (D), Marco van Gelderen (D) and Enno Masurel * \\ Department of Management and Organization, School of Business and Economics, \\ Vrije Universiteit Amsterdam, 1081 HV Amsterdam, The Netherlands; e.p.schraven@vu.nl (E.S.); \\ elco.van.burg@vu.nl (E.v.B.); m.w.van.gelderen@vu.nl (M.v.G.) \\ * Correspondence: e.masurel@vu.nl
}

Received: 20 November 2020; Accepted: 8 December 2020; Published: 21 December 2020

\begin{abstract}
Crowdfunding has quickly gained popularity in recent years, providing an additional way for entrepreneurial individuals and organizations (creators) to attract funds for their projects. Scholars have been interested in predicting the success of crowdfunding campaigns, by relating campaign characteristics to the actual success of these campaigns. We take one step back by studying the cognitive processes of the crowd. This paper uses an experimental approach to establish whether participants' predictions on the success of crowdfunding campaigns based on first impressions are as positive and as accurate as those derived from more thorough analyses. We employ a two-study replication design, in which individuals estimate the success of crowdfunding campaigns in two conditions: with limited time and with unlimited time. The results show that prediction accuracy in both conditions is equal, yet shorter time availability results in assessments that are more negative. We discuss implications for creators and for funders.
\end{abstract}

Keywords: crowdfunding; prediction; accuracy; positivity

\section{Introduction}

The landscape of entrepreneurial finance has undergone some drastic changes in recent years and has welcomed a number of new financing forms into the arena (Block et al. 2018a). One of these forms is crowdfunding. Mollick (2014, p. 2) defined crowdfunding as "the efforts by entrepreneurial individuals and groups-cultural, social, and for-profit - to fund their ventures by drawing on relatively small contributions from a relatively large number of individuals using the internet, without standard financial intermediaries". Crowdfunding enables enterprising individuals and organizations to raise money from large numbers of small-scale funders to finance their new product, service, project or venture. Those seeking funding advertise their ideas on crowdfunding platforms-that is, websites that provide a single webpage enabling founders to explain ideas and entice potential investors to make an investment. A financial target is set for the amount to be raised, as well as one or more rewards or repayment methods. Throughout this paper, crowdfunding individuals and organizations jointly are referred to as creators (or founders).

By definition, crowdfunding involves a large number of potential funders being approached, rather than a single professional bank manager or venture capitalist. The crowd thus does not consist of just professional investors; research has shown that funders vary greatly in terms of their expertise and motivation to fund (Allison et al. 2015; Cholakova and Clarysse 2015; Gerber et al. 2012). Moreover, the decision process of funders is likely to differ from that of professionals as the amounts involved are relatively small. As a consequence, funders may rely more on first impressions and heuristics compared to a decision where more is at stake. 
The reliance on first impressions and heuristics is furthered by the enormous supply of crowdfunding projects. Funders are able to view thousands of projects on hundreds of platforms asking for their funds, which entails significant information overload. On the other hand, funders have limited information to consider before making the decision to fund a campaign. They usually lack information obtained via personal interaction, as is common in traditional ways of financing new ventures. Both information overload and information scarcity prevent consideration of all relevant information and thus promote the reliance on heuristics.

Those seeking funding face the challenge of standing out among a multitude of other campaigns and ensuring that viewers' favorable heuristics are activated so that they arrive at a positive assessment of the project's benefits and success. There are fewer possibilities to signal quality and professionalism than there are in traditional ways of attracting capital, where personal interaction between investors and entrepreneurs normally occurs (Mollick 2014). Therefore, for those who seek funding it is important to understand the specifics of the factors and processes that make some crowdfunding campaigns more convincing and persuasive than others. Therefore, it is not surprising that one of the most researched topics within the crowdfunding literature concerns the identification of characteristics of campaigns that are indicative of their success. The vast majority of extant literature has focused on predicting the actual success of crowdfunding campaigns, often based on web-crawled data (e.g., Mollick 2014; Greenberg et al. 2013; Ullah and Zhou 2020).

We take one step back and add to this literature by taking the deliberations of the crowd into account. Given the likelihood that funders will give most proposals only limited attention, we want to know how this affects their judgements. Specifically, we focus on positivity and accuracy in relation to first impressions of crowdfunding campaigns.

The question of positivity is particularly relevant for those seeking funding. Studying people's assessments of crowdfunding success and its antecedents is important as this assessment represents an important step towards making an actual investment. Indications of the perceived likelihood of crowdfunding campaign success are linked to individual decisions to fund (Genevsky et al. 2017). For creators, it affects how the campaign could be successfully designed: if people make more positive predictions when their assessment is based on first impressions, creators should prioritize optimization of the features that cause funders to form these positive first impressions. On the other hand, if first impressions lead to more negative assessments, funding seekers should give priority to avoiding negative cues, stimulate funders to carefully study all provided information, and provide extensive and detailed information that may counteract an initial negative first impression.

The question of accuracy is particularly relevant for funders. Even though they get their money back if the financial goal is not met, experiencing the realization of a successful project is one of the crowd's main reasons for contributing to crowdfunding campaigns (Hemer 2011). For funders it is of interest to know whether they can trust their initial judgement or should analyze campaigns extensively, before they pledge their money.

The issues addressed above lead to the following research question: What is the effect of assessment time on the positivity and accuracy of crowdfunding campaign success evaluations? In answering our research question, we are guided by Simon's (1972) notions of heuristics and bounded rationality, and by Stanovich and West's (2000) distinction between system 1 (fast, automatic, unconscious) and system 2 (slow, conscious, deliberate, effortful) processing (see Kahneman 2011). In answering our research question pertaining to positivity, we particularly base our reasoning on category diagnosticity theory (Skowronski and Carlston 1989). With regard to our research question pertaining to accuracy, our reasoning is particularly informed by the literature on thin slices (Ambady 2010).

We employ an experimental two-study replication design in which participants predict the success of crowdfunding campaigns either in a condition where they base their judgement on first impressions or in a condition where they use more time and information to arrive at their assessment. Both studies also show that judgements based on quick impressions are equally accurate compared to when more time is available, and more information is processed. In study 2 the crowd evaluates the campaigns 
less positively when assessments are based on short assessments compared to longer investigations. In study 2, the assessment time of the short condition was significantly decreased compared to study 1 , creating a more significant difference between the short and long duration conditions

This paper adds to the crowdfunding literature by taking the deliberations of the crowd into account. In particular, we demonstrate that impressions based on limited processing time are less positive, but equally accurate, compared to those decisions where more time is taken to study the campaign. Moreover, our study contributes to the literature on decision-making. First, we test an unexplored aspect of heuristic-based judgements by evaluating whether such judgements tend to be more positive or negative. The research evidence has so far been circumstantial, and we provide conceptual arguments and a direct test pertaining to this question. Second, with regard to accuracy there is disagreement in the literature (to be discussed below) as some evidence shows that decisions based on first impressions are flawed and inferior compared to those based on more thorough analyses, while others have found the opposite. Our study contributes by explicitly focusing on these puzzling findings as reported in the literature and finds support for the second position.

\section{Theory}

\subsection{Crowdfunding Demand and Supply}

For people and organizations with ideas for new products, services, or projects it can be difficult to obtain financial resources, particularly if the venture is novel and creative, and the founder has no track record and limited endowments. It is difficult for banks and venture capitalists to assess risks and therefore to invest in these new ventures, creating a funding gap for the early stages of new firm development (Ley and Weaven 2011). Aggravating this problem, the worldwide financial crisis of 2008 has caused banks to tighten their policies. Therefore, enterprising individuals have started looking for new opportunities to attract financial capital. This has facilitated the fast growth of the alternative finance markets, including microfinance, peer-to-peer lending, invoice trading, and crowdfunding (Block et al. 2018b; Bruton et al. 2015; Ante et al. 2018).

The large growth of social networking sites and applications, combined with the possibilities of Web 2.0, has facilitated the rise of crowdfunding. Through crowdfunding platforms, the creator can reach a large pool of potential funders. Another advantage of crowdfunding is the lack of formal rules, providing even those with limited access to mainstream finance channels with a chance to realize their ideas. Furthermore, Kuppuswammy and Roth (2016) found evidence that successful crowdfunding has a positive effect on the creator receiving additional financing. Moreover, crowdfunding campaigns provide valuable information about demand for the product, service, or project, and can serve as a low-cost marketing tool (Mollick 2014; Miglo 2020; Bernardino and Santos 2020). In addition, investors in crowdfunding campaigns have the opportunity to invest small amounts of money. This lowers the entry barrier to investing and allows investors to have a diversified portfolio, even when they possess limited resources. On the platform, the funder can select from a large pool of projects.

Several forms of crowdfunding exist, such as donation-based, reward-based, loan-based, and equity-based crowdfunding (Mollick 2014). This paper investigates predictions of the success of crowdfunding campaigns using reward-based crowdfunding, which is one of the most common forms of crowdfunding and provides valuable advantages over other ways of financing a venture. Here, campaigns make use of non-financial rewards in return for funders' financial support, such as pre-sale of products, vouchers (for instance, free menus in a newly opened restaurant), tickets to performances, and recognition (such as one's name on the seat of a newly built theatre). As opposed to debt-based and equity-based crowdfunding, in reward-based crowdfunding, the creator does not pay interest rates on loaned money and does not give away control or ownership of his/her organization in the form of shares. As reward-based crowdfunding often uses the presale of eventual products as a reward to the customer, it establishes demand for a product or service before production or delivery is commenced. It often takes the form of financial bootstrapping, where founders are 
financed by advance payments that funders give in exchange for the subsequent delivery of a product or service (Block et al. 2018a).

Crowdfunding is relevant to the research field of risk and financial management. Procurement of funds for the enterprise is part of financial management. Crowdfunding helps to reduce a number of risks for creators. Firstly, by borrowing from a crowd of funders, in comparison to bank loans based on collateral, creators do not risk losing their collateral. Secondly, as crowdfunding campaigns do not only generate financial funding but also valuable information about demand for the product or service, it reduces demand uncertainty (Miglo 2020). Thirdly, as reward-based platforms such as Kickstarter delete failed campaigns, the risks of a failed campaign is limited, as there is restricted reputation risk. In short, reward-based crowdfunding is a form of crowdfunding that can significantly lower the risk for the creator (Schwienbacher 2018). Reward-based crowdfunding also poses limited risks for investors. It is true that investors risk that the creator will not deliver the rewards. However, not only is the amount to be invested limited, the risk is being shared by many other small investors, and the money is only transferred if the campaign meets the financial goal.

One of the most researched topics within the crowdfunding literature concerns the characteristics of campaigns that are indicative of their success. Studies of the characteristics of crowdfunding campaigns and their relation to campaign success have typically considered web-crawled data to predict the actual success of campaigns (e.g., Mollick 2014; Greenberg et al. 2013). This study instead turns towards the funders and focuses on the crowd's prediction positivity and accuracy. We are interested in characteristics that make funders believe the campaign will be successful. Creators want to create their campaigns in such a way that funders arrive at a positive assessment; conversely, funders want to participate in projects that are ultimately successful (Hemer 2011). Therefore, for funders it is important to establish the characteristics that are connected to prediction accuracy. Ultimately, the positivity and the accuracy of predictions of crowdfunding campaigns are correlated: if many funders believe the campaign will be successful, it will turn out to be so.

As explained above, funders can potentially choose from thousands of projects, and each of these projects presents information on their crowdfunding page. Some funders will study just a few projects extensively, but others will browse through a variety of projects to see whether there is a venture they wish to support. Even among those who are invited by someone in their network to support a project, some will study the project thoroughly whereas others will do so only briefly. Particularly for those who give projects only limited attention, the notions of heuristics and bounded rationality are relevant (Simon 1957). When there is limited time to process information, not all information can be considered. Decision makers deal with processing constraints by being selective in what they devote attention to (Simon 1957). This selective processing of information relies on the use of heuristics, or mental shortcuts (Simon 1957; Gigerenzer and Gaissmaier 2011). Heuristics aid in decision-making by reducing the amount of effort spent on the decision. Shah and Oppenheimer (2008) proposed that this reduction happens by examining fewer cues, reducing effort spent retrieving cues, simplifying the weight of cues, integrating less information, and examining fewer alternatives.

When making fast decisions by relying on heuristics, individuals depend more on what Stanovich and West (2000) referred to as system 1, and less on system 2. According to dual-process theories of judgements and decision-making (Chaiken and Trope 1999), information processing and the formation of judgements takes place in two systems (Stanovich and West 2000; Kahneman 2011). In system 1, processing is swift, automatic, unconscious, immediate, and effortless. Bargh and Chartrand (1999) argued that a very large portion of everyday life is determined by this first information processing system. On the other hand, system 2 processing takes effort, and is slow, deliberate and conscious. This enables individuals to analyze information attentively (Dane and Pratt 2007). Humans' capacity to consciously process new information is severely limited, and humans therefore seek to minimize conscious cognitive effort by resorting to automatic processing of information whenever possible. Only a very small percentage of decisions are processed deliberately. The two systems interact and complement each other, and both systems are capable of accuracy and of errors (Frese 2007). 
Each system assigns a value to a decision, independent of the other, on the basis of its own method of evaluation. Thus, the final output that drives decisions is a combination of the evaluations of the two systems (Mukherjee 2010). The less time there is to process information, the less system 2 can play a role. These ideas are well accepted in the research domain of the psychology of advertising, where dual processes logic is ubiquitous. For example, Fennis and Stroebe (2010) discern pre-attentive analysis, focal attention, comprehension, and elaborative reasoning, and conclude that automatic, non-conscious processing is more influential during pre-attentive analysis and during focal attention, whereas reflective, conscious processes play an important role during comprehension and evaluation. Against the backdrop of systems 1 and 2, bounded rationality and the use of heuristics, we will now develop our hypotheses as to the positivity and accuracy of predictions of crowdfunding success when there is limited versus unlimited time to process information.

\subsection{Processing Time and Positivity of Predictions}

The first issue of the research question we investigate is how depth of processing is associated with the positivity of assessments. Are funders, who can choose out of hundreds or thousands of projects, equally positive when they extensively study these projects, compared to when they make up their mind immediately? For a crowdfunding campaign to be effective, the crowd has to reach a positive judgement. In answering our question, we first turn to the notion of negativity bias. There is extensive research evidence that individuals give greater value, importance, and weight to negative events, objects, and personal traits (Rozin and Royzman 2001). The greater general potency of negative events is at the core of prospect theory (Kahneman and Tversky 1979). In decision-making, potential costs are more influential than potential gains, a phenomenon referred to as loss aversion (Kahneman and Tversky 1979), which is logical from an evolutionary perspective (Baumeister et al. 2001). A person who ignores the possibility of a positive outcome may later experience significant regret at having missed an opportunity for pleasure or advancement, but no immediate harm is likely to result. In contrast, a person who ignores a threat even once may lose everything. Survival requires urgent attention to possible negative outcomes, but there is less urgency with regard to positive ones.

For our study, the relevant question is whether people arrive at more negative or more positive assessments when they have limited versus unlimited opportunities for information processing. We argue that people arrive at more negative judgements when they have limited time to process information. At the physiological level, research shows that negative stimuli have greater influence on neural responses compared to positive stimuli (Ito et al. 1998). This extends to the unconscious, with negative information being taken into account even if it is not consciously processed; and to the phenomenon of automatic vigilance, which refers to the direction of attentional capacity to negative stimuli outside of the perceiver's intention or control (Pratto and John 1991). The rapid detection of negative information has been confirmed in several empirical studies (e.g., Hansen and Hansen 1988; Oehman et al. 2001).

In the context of crowdfunding campaigns, it should be noted that cues are not inherently positive or negative. Therefore, category diagnosticity theory (Skowronski and Carlston 1989) is particularly relevant to our arguments. In the category diagnosticity model, as in the evaluation of crowdfunding campaigns, the informativeness of a cue fundamentally relies on people's implicit theories about the relations between cues and categories. However, once beliefs are formed about what constitutes a negative or positive cue, negative cues are generally perceived as more diagnostic than are moderate or positive cues. Skowronski and Carlston (1989) proposed that negative cues are more diagnostic than positive ones because the category requirements of consistency are more stringent for good than for bad cues. To be categorized as good, one has to be good all of the time (consistently). To be categorized as bad, a few bad acts are sufficient, and presumably hardly anyone is consistently bad. The relative power of negative contamination is embedded in an age-old Russian adage: "A spoonful of tar can spoil a barrel of honey, but a spoonful of honey does nothing for a barrel of tar." Hence, negative cues carry more weight for ruling out a positive assessment compared to positive cues for ruling out 
a negative assessment. Similarly, those making hiring decisions use unfavorable information as a basis for rejecting candidates to a greater extent than they use favorable information as a basis for hiring them (Baumeister et al. 2001), and consumers predominantly rely on negative information when using online reviews (Park and Nicolau 2015).

However, the effects of negativity bias can be superseded by other goals, although these goals are unlikely to completely eliminate these effects. When perceivers can determine what information is made available to them (as in interviews), the goal to be accurate can make them less biased in seeking negative information and to form less negatively biased impressions, even when they have negative expectancies about the target (Neuberg 1989). Negativity bias applies to both system 1 and system 2. However, with less time to process information, a focus on negative cues is involuntary. With more time to process information, individuals can consciously decide to seek counterevidence and to override initial negative impressions (Neuberg 1989). Without such efforts, negativity bias dominates. Hence, we posit:

Hypothesis 1 (H1). Predictions of the success of crowdfunding campaigns based on short duration assessments are more negative than predictions based on more lengthy investigations.

\subsection{Processing Time and Accuracy of Predictions}

A classic notion in dual-process theories is that the reduction of effort trades off against accuracy (Bogacz et al. 2010; Wickelgren 1977). Kahneman (2011) presents numerous studies with many collaborators, showing that the judgements produced by system 1 are prone to a wide range of errors. System 1 cognitive processing uses associative memory to generate a coherent story to explain the judgement, and in doing so is subject to biases pertaining to areas such as availability and representativeness. It is also subject to confirmation bias, as first impressions influence subsequent judgements (Mynatt et al. 1977; Nickerson 1998; Oswald and Grosjean 2004; Rabin and Schrag 1999). People tend to use new data to confirm, rather than challenge existing beliefs. When there is limited time to process information, individuals rely more on heuristics based on system 1 processing, so one would expect biased and therefore less accurate predictions.

However, other streams of research have reported on the accuracy of immediate judgements. The literature on "thin slices" revolves around the idea that people can make relatively accurate judgements based on small pieces—or thin slices—of information (Ambady and Rosenthal 1992). Most of the research in this area has been concerned with interpersonal judgements, and Ambady et al. (2006) reported that very brief observations can serve as a basis for consistently accurate assessments of personality traits, motivations, trustworthiness and affect. Thin-slice methodologies have also been applied to demonstrate the importance of first impressions in the evaluation of websites (Kim and Fesenmaier 2008; Lindgaard et al. 2006; Peracchio and Luna 2006). For example, Kim and Fesenmaier (2008) showed that people arrive at quick and correct judgements of how informative, usable, credible, inspirational, involved and interactive a website is. According to the capacity principle (Dijksterhuis and Nordgren 2006), the unconscious mind is able to process much larger amounts of information compared to the conscious mind, the latter often uses only a subset of information, leading to subpar decision-making. This corresponds to the findings of Wilson and Schooler (1991), who showed that an analysis of reasons may stress the importance of non-optimal criteria, causing people to base their decisions on these criteria.

We expect that even when a crowd bases their judgements on first impressions, the crowd is able to predict the success of campaigns with equal accuracy compared to when a longer time is taken to study the provided information. Conceptually, both first impressions and elaborate assessments can lead to accurate predictions; the empirical literature described above has shown the merits of both but has not conclusively supported the superiority of one over the other. Hence, we posit: 
Hypothesis 2 (H2). Predictions of the success of crowdfunding campaigns based on short duration assessments are as accurate as predictions based on more lengthy investigations.

\section{Study 1}

\subsection{Research Design}

This paper used an experimental design to determine whether the predictions of crowdfunding campaign success based on short versus longer duration assessments differ in terms of positivity and accuracy. As is increasingly common and expected in the social sciences (Miller and Bamberger 2016), we test our hypotheses in two separate studies. Here, we introduce the first study. Participants (raters) were asked to estimate the success of a selection of crowdfunding campaigns, for which the outcomes were not shown (half of the selected projects were in fact successful in reaching their monetary goal, while the other half were not). To study the importance of first impressions, two conditions were created: the "long" condition gave the participants minimum, but no maximum, limits on time and information used to provide an assessment; the "short" condition capped participants' time and information so that they had to rely on first impressions. As a research assistant was directly observing the participant, no attention test was deemed necessary.

\subsection{Crowdfunding Campaign Sample}

A sample of 96 crowdfunding campaigns was taken from Kickstarter. Half of the selected campaigns had been successful, half unsuccessful. The reason why we chose this US reward-based crowdfunding platform is its representativeness; it is the largest crowdfunding platform in the world in terms of numbers of projects and funders (Mollick 2014). Kickstarter uses a reward-based system, which means people are rewarded for their financial support in one or more non-financial manners. Often-used rewards are the pre-sale of products, services, vouchers, tickets to performances, thank-you notes, and meet-and-greets with the project team. Kickstarter uses a threshold pledge system, meaning the money from investors is first pledged to the project, and only when the threshold (that is, the monetary goal of the campaign) is reached are the funds actually transferred to the project.

As the crowdfunding campaigns used in our study had already ended, their pages showed whether the projects were successful. Therefore, manipulated screenshots were created, showing everything a Kickstarter project page displays while the campaign is active, with a few exceptions. Namely, the amount of money already raised was left out, and the number of comments left by the public was also omitted because Kickstarter only allows people who have invested in the project to leave a comment. Finally, the number of updates was omitted as it correlates with the success of campaigns (Block et al. 2018b). Thus, the raters were shown the campaign as if it was first launched.

As Kickstarter does not display past unsuccessful projects, a website named Kicktraq, which has crawled data available on Kickstarter projects, was used to find these failed attempts. At the time we selected suitable crowdfunding projects, the success rate on Kickstarter was about $40 \%$ (Kickstarter Stats 2015). Participants were not informed of the base rate of Kickstarter projects or sample base rates ( $50 \%$ successful), in order to make sure that the raters' impressions would not be led by base rate expectations.

To increase the generalizability of our findings, we compared the respondents' predictions in two sectors: the technology sector and the creative sector. Whereas the former sector is simply the "technology" project category on Kickstarter, the latter is composed of the following categories: art, comics, crafts, dance, design, fashion, film and video, food, music, photography, publishing, and theatre. Both sectors are well represented on the platform. Half of the selected campaigns came from the technology sector, half from the creative sector.

As further controls for the effects of the experimental conditions, a number of characteristics were taken from the project pages as they may also impact the positivity and accuracy of predictions by the participants, and therefore were taken to serve as control variables. These characteristics included the 
presence of a video pitch, the monetary goal, the number of rewards, whether the creator was portrayed as an individual or an organization, the number of projects the creator had started on Kickstarter before the project in question, and how many projects the creator had funded on Kickstarter. In order to prevent effects arising from the skewness of the distribution of monetary aims, the monetary goal was categorized into five groups. Table 1 shows an overview of the campaign characteristics of this study (first column).

Table 1. Crowdfunding campaign descriptives.

\begin{tabular}{|c|c|c|c|c|c|c|}
\hline & \multirow{2}{*}{ Category } & \multicolumn{3}{|c|}{ Study $1(N=96)$} & \multicolumn{2}{|c|}{ Study $2(N=90)$} \\
\hline & & $N$ & & & $N$ & $\%$ \\
\hline \multirow{2}{*}{ Creator } & Individual & 53 & \multicolumn{2}{|c|}{55.2} & 52 & 57.8 \\
\hline & Organization & 43 & \multicolumn{2}{|c|}{44.8} & 38 & 42.2 \\
\hline \multirow[t]{2}{*}{ Video } & Yes & 78 & \multicolumn{2}{|c|}{81.3} & 67 & 74.4 \\
\hline & No & 18 & \multicolumn{2}{|c|}{18.8} & 23 & 25.6 \\
\hline \multirow[t]{5}{*}{ Goal (\$) } & $0-10,000$ & 40 & \multicolumn{2}{|c|}{41.7} & 43 & 47.8 \\
\hline & $10,001-50,000$ & 37 & \multicolumn{2}{|c|}{38.2} & 32 & 35.6 \\
\hline & $50,001-100,000$ & 14 & \multicolumn{2}{|c|}{14.6} & 7 & 7.8 \\
\hline & $100,001-250,000$ & 5 & \multicolumn{2}{|c|}{5.2} & 7 & 7.8 \\
\hline & $>250,000$ & 0 & \multicolumn{2}{|c|}{0} & 1 & 1.1 \\
\hline \multirow[t]{3}{*}{ Sector } & Technology & 48 & \multirow{2}{*}{\multicolumn{2}{|c|}{$\begin{array}{l}50.0 \\
50.0\end{array}$}} & 90 & 100 \\
\hline & Creative & 48 & & & 0 & 0 \\
\hline & Range & Mean & SD & Range & Mean & SD \\
\hline Projects Created & $0-32$ & 0.81 & 3.36 & $0-10$ & 1.08 & 1.96 \\
\hline Projects Funded & $0-75$ & 4.93 & 10.76 & $0-47$ & 3.69 & 7.77 \\
\hline Rewards & $1-31$ & 9.30 & 5.45 & $1-62$ & 8.63 & 7.38 \\
\hline
\end{tabular}

\subsection{Participant Sample}

Study 1 employed a sample of 16 participants, who each judged 24 campaigns. All participants have a good understanding of the English language and are familiar with the concept of crowdfunding. Participants varied in age between 21 and 57, with 14 men and 2 women. As experience may affect the positivity and accuracy of predictions, we equally sampled people who had not previously invested in a crowdfunding campaign, and a group of experienced crowdfunders. The first group of eight was recruited through the network of a research assistant; the second group was contacted through a "shout-out" on Twitter by the owner of the largest crowdfunding consultancy agency in The Netherlands (Douw \& Koren). The eight members of this second group had invested in between 10 and 75 crowdfunding campaigns (36 on average). All participants received a small reward.

\subsection{Short and Long Duration Conditions, and Procedure}

The participants were provided with instructions explaining that screenshots of crowdfunding campaigns would be shown and that their task was to predict whether the financial goal of the campaign would be reached. In the short duration condition, which captured first impressions, the participants watched the first $20 \mathrm{~s}$ of a pitch video, after which they studied the project's website (screenshot) for a maximum of $1 \mathrm{~min}$. In the long duration condition, the participants saw the entire video and took as long as they wanted to study the website. Subsequently, the participants predicted whether the project was successful in reaching its monetary target with this specific campaign. The mean time for the short condition was $56 \mathrm{~s}$, and for the long condition $160 \mathrm{~s}$-a significant difference $(t=9.99, p<0.001)$.

In sum, of the total of 96 crowdfunding campaigns, each of the 16 participants assessed 24 campaigns, equally divided over successful versus unsuccessful, technology sector versus creative sector, and short condition versus long condition, resulting in 384 observations. 


\subsection{Analyses and Results}

The correlations between key variables of study 1 are shown (bottom left) in Table 2. We see that both positivity and accuracy show a number of significant correlations. It is striking to see that experience is not related to any other variable.

Table 2. Bivariate correlations matrix (study 1 bottom left; study 2 top right).

\begin{tabular}{|c|c|c|c|c|c|c|c|c|c|c|c|}
\hline & 1 & 2 & 3 & 4 & 5 & 6 & 7 & 8 & 9 & 10 & 11 \\
\hline 1 Creator & - & $-0.31 * *$ & $-0.11^{* *}$ & $-0.11^{* *}$ & -0.03 & $-0.23 * *$ & -0.01 & $-0.24 * *$ & $-0.17 * *$ & -0.03 & - \\
\hline 2 Video & $-0.33^{* *}$ & - & -0.04 & $-0.19 * *$ & $-0.15^{* *}$ & $-0.22 * *$ & -0.00 & $-0.32 *$ & $-0.06^{*}$ & -0.05 & - \\
\hline 3 Projects Created & -0.08 & -0.04 & - & $-0.60^{* *}$ & $-0.12 * *$ & $-0.08^{* *}$ & -0.03 & $-0.42 * *$ & $-0.08 * *$ & $-0.07 *$ & - \\
\hline 5 Goal & $-0.27^{* *}$ & $-0.28 * *$ & $-0.15^{* *}$ & -0.02 & - & -0.05 & -0.02 & $-0.09 * *$ & -0.04 & -0.02 & - \\
\hline 6 Rewards & $-0.24^{* *}$ & $-0.29 * *$ & $-0.36^{* *}$ & $-0.12 *$ & -0.00 & - & -0.03 & $-0.36 * *$ & $-0.014 * *$ & $-0.06 *$ & - \\
\hline 7 Condition & -0.00 & -0.00 & -0.00 & $-0.28^{* *}$ & -0.00 & -0.00 & - & -0.02 & $-0.11 * *$ & -0.03 & - \\
\hline 10 Accuracy & -0.00 & -0.09 & -0.00 & -0.08 & $-0.12 *$ & -0.02 & -0.02 & $-0.12 *$ & -0.01 & - & - \\
\hline 11 Experience & -0.00 & -0.00 & -0.00 & -0.00 & -0.00 & -0.00 & -0.01 & -0.00 & -0.06 & -0.04 & - \\
\hline 12 Sector & $-0.23 * *$ & -0.05 & -0.10 & -0.04 & $-0.29 * *$ & $-0.16 * *$ & -0.01 & -0.00 & $-0.19 * *$ & -0.09 & -0.00 \\
\hline
\end{tabular}

${ }^{*} p<0.05 ;{ }^{* *} p<0.01$; Categorical Variables: Creator: Individual $=0$, Organization $=1$; Video: Absent $=0$, Present $=1$; Condition: Short duration $=0$, Long duration $=1$; Actual Success: No success $=0$, Success $=1$; Accuracy: Not accurate $=0$, Accurate $=1$; Positivity: Not positive $=0$, Positive $=1$; Experience: No experience $=0$, Experience $=1$; Sector: Technology $=0$, Creative $=1$.

In order to reveal whether short assessments and more lengthy analyses differ in terms of positivity, we employed a generalized linear mixed model (GLMM). We used a GLMM because we had to include random effects corresponding to the different groups of participants. As can be seen in Table 3, only creator and rewards proved to be significant (with significance values lower than 0.05). Thus, the time condition has no influence on positivity, and Hypothesis 1 is not supported.

Table 3. Generalized linear mixed model (study $1, N=384$ ).

\begin{tabular}{lcccccccc}
\hline & \multicolumn{3}{c}{ Positivity } & \multicolumn{5}{c}{ Accuracy } \\
\cline { 2 - 9 } & Coefficient & S.E. & $t$ & Sig. & Coefficient & S.E. & $t$ & Sig. \\
\hline Intercept & -1.17 & 1.99 & -0.59 & 0.56 & 0.76 & 1.97 & 0.38 & 0.70 \\
Creator & 0.79 & 0.26 & 3.01 & 0.00 & -0.49 & 0.25 & -1.94 & 0.05 \\
Video & -0.20 & 0.35 & 0.57 & 0.57 & -0.70 & 0.34 & -2.04 & 0.43 \\
Projects Created & -0.03 & 0.04 & -0.69 & 0.49 & 0.04 & 0.04 & 0.97 & 0.34 \\
Projects Funded & 0.01 & 0.01 & 1.20 & 0.23 & -0.01 & 0.01 & -1.30 & 0.20 \\
Goal (\$) & & & & & & & & \\
$\quad$ 100,001-250,000 & -0.63 & 0.58 & -1.09 & 0.28 & 0.62 & 0.55 & 1.14 & 0.26 \\
$\quad$ 50,001-100,000 & -0.30 & 0.40 & -0.76 & 0.45 & 1.50 & 0.41 & 3.64 & 0.00 \\
$\quad$ 10,001-50,000 & -0.20 & 0.31 & -0.67 & 0.51 & 0.77 & 0.29 & 2.62 & 0.01 \\
$\quad$ 0-\$10,000 & 0 a & & & & 0 & & & \\
Rewards & 0.07 & 0.03 & 2.59 & 0.01 & -0.00 & 0.03 & -0.04 & 0.97 \\
Condition & -0.21 & 0.22 & -0.97 & 0.33 & 0.08 & 0.22 & 0.37 & 0.71 \\
\hline
\end{tabular}

Probability distribution: Binomial. Link function: Logit. ${ }^{\mathrm{a}}=$ Redundant.

Moving to the accuracy of the predictions in the short and long conditions, when people are given just a minute (screenshot) and $20 \mathrm{~s}$ (video) to assess a crowdfunding campaign, they predict success with a $62 \%$ accuracy rate. A non-parametric binomial test shows that this rate is significantly higher than expected by chance ( $\mathrm{P}=0.5), \mathrm{z}=3.24, p=0.0001$. Using the same test reveals that when the participants are provided with unlimited time to study the website, the accuracy rate is $61 \%$ and above chance levels $(\mathrm{P}=0.5), \mathrm{z}=2.96, p=0.0001$.

The results show that the time condition did not have a significant effect on accuracy. Only the creator and two goal variables did, with significance values lower than 0.05 (see Table 3). These results support Hypothesis 2. 
One explanation for our failure to confirm Hypothesis 1 may be that the time frame for the short condition was not short enough, making the conditions too similar in terms of information processing. In our next study, therefore, we shortened the time frame for the short condition.

\section{Study 2}

\subsection{Research Design}

In study 2 we expected both hypotheses to be supported if the limitations associated with the short condition were made stricter. Note that, in this study, the assessment in the long and short time conditions does not apply to the same projects (in the first study the same projects were assessed both in the long and short time conditions). Nevertheless, we expected more negative predictions if the short condition allowed less time and provided less information. Furthermore, as neither experience nor sector (technological/creative) turned out to have an impact in study 1 , we did not include these distinctions in the design of study 2. Another factor that may influence the results is that we had a limited number of participants judging a variety of campaigns in study 1 . We therefore increased the number of participants in study 2.

We sampled a new set of 90 projects, all of them in the technology category, half of which were successful and the other half unsuccessful. The same procedures applied as for study 1.

\subsection{Participant Sample}

A sample of 184 third-year Bachelor students of a Dutch university (Vrije Universiteit Amsterdam) participated in the study. These students' ages were in the range 18-26, 20.2 on average, and $42 \%$ were female. They were aware of the concept of crowdfunding but had very limited experience with actually funding projects. In return for participating in the study, the students were awarded with official credits, which they needed to receive to obtain their Bachelor's degree. After starting with 209 participants and discarding 25 who did not finish the survey or failed the attention test (in which participants were asked to put a slider to 70 , this number was randomly chosen), the sample consisted of 184 participants.

\subsection{Short and Long Duration Conditions, and Procedure}

The study was digitized using a survey program. First, the experiment was explained to the participants on-screen, after which they entered demographic information and started the experiment. The students were presented with a number of crowdfunding projects, which were randomly selected from the sample. These were then randomly assigned to one out of two conditions: short duration (capturing short assessments) or long duration (facilitating more lengthy analysis). To assess whether participants were able to predict crowdfunding success from short time frames, in the short duration condition just the first 10 seconds of a pitch video were shown, and participants were then allowed to browse an edited screenshot of the campaign for $10 \mathrm{~s}$. In the long duration condition, it was mandatory to inspect the video and the screenshot for a minimum of $60 \mathrm{~s}$ each, with no maximum time limit. If the pitch video was shorter than 1 minute, the minimum amount of time to be spent was the length of the video. The mean time for the short condition was $26.9 \mathrm{~s}$ (this includes idle time before and after playing the $10 \mathrm{~s}$ video snippet before continuing to the screenshot), the mean time for the long condition was $173.9 \mathrm{~s}-\mathrm{a}$ highly significant difference $(t=32.02, p<0.001)$. After this, the participants selected either "yes" or "no", depending on whether they thought the project was going to be successful in reaching its monetary target. After completing five assessments, students were presented with an attention test. After this, as long as the timer for the total time of the survey was under $19 \mathrm{~min}$, the students were presented with another project. This procedure eventually resulted in 1355 observations, of which 697 belonged to the short condition and 658 to the long condition. 


\subsection{Analyses and Findings}

Table 2 (now top right) shows the correlations between the key variables of study 2. Again, we see that both positivity and accuracy show a number of significant correlations with a range of other variables. As in study 1, a GLMM was used to investigate the effect of the condition on the positivity of the prediction, because we had to include random effects corresponding to the different groups of raters. As can be seen in Table 4, the participants were more positive when creators were portrayed as organizations, and when participating in the long condition, thereby supporting H1. The number of rewards also had a positive effect on the positivity of the prediction, as did the number of Kickstarter projects the creator had previously run, all with significance values lower than 0.05 .

Table 4. Generalized linear mixed model (study 2, $N=1334$ ).

\begin{tabular}{lcccccccc}
\hline & \multicolumn{3}{c}{ Positivity } & \multicolumn{3}{c}{ Accuracy } \\
\cline { 2 - 9 } & Coefficient & S.E. & $t$ & Sig. & Coefficient & S.E. & $t$ & Sig. \\
\hline Intercept & -0.55 & 1.94 & -0.28 & 0.78 & 0.32 & 1.97 & 0.16 & 0.87 \\
Creator & 0.78 & 0.19 & 4.09 & 0.00 & -0.29 & 0.20 & -1.42 & 0.16 \\
Video & 0.21 & 0.22 & 0.95 & 0.34 & -0.19 & 0.23 & -0.81 & 0.42 \\
Projects Created & 0.12 & 0.05 & 2.25 & 0.02 & 0.05 & 0.06 & 0.85 & 0.40 \\
Projects Funded & -0.01 & 0.01 & -0.42 & 0.67 & 0.00 & 0.02 & 0.10 & 0.92 \\
Goal (\$): & & & & & & & & \\
$\quad$ 250,000 & -0.66 & 1.00 & -0.65 & 0.51 & 0.99 & 1.04 & 0.96 & 0.34 \\
100,001-250,000 & 0.67 & 0.33 & 2.00 & 0.05 & -0.31 & 0.35 & -0.88 & 0.38 \\
50,001-100,000 & 0.30 & 0.35 & 0.88 & 0.38 & 0.06 & 0.36 & 0.16 & 0.88 \\
$\quad$ 10,001-50,000 & 0.24 & 0.19 & 1.26 & 0.21 & 0.31 & 0.21 & 1.49 & 0.14 \\
$\quad$ 0-10,000 & 0 & & & & 0 & & & \\
Rewards & 0.04 & 0.01 & 2.48 & 0.01 & 0.01 & 0.01 & 0.90 & 0.37 \\
Condition & -0.53 & 0.12 & -4.48 & 0.00 & -0.17 & 0.18 & -1.43 & 0.15 \\
\hline
\end{tabular}

Regarding the accuracy of the predictions, in the long condition participants were able to correctly predict the success of campaigns with an accuracy of 59\%. In the short condition, where participants were allowed to watch the projects and videos for a mere 10 seconds each, they still achieved an accuracy rate of $56 \%$. To investigate the effect of the different time conditions on the accuracy of the crowd's estimations of campaign success, we again use a GLMM (see Table 4). The results show that the time condition has no significant influence on accuracy. Therefore, the results support Hypothesis 2. No other variables are found to influence prediction accuracy (no significance values lower than 0.05 ).

\section{Discussion and Conclusions}

First, our study assesses whether judgements based on short assessments tend to be more or less positive than those based on investigations that are longer. In study 1 , we found no difference between these two conditions, leading us to reduce the time and information provided in the short condition. In study 2, the condition was found to have a significant effect, with campaigns being given fewer positive assessments when they were judged in the short duration condition. This pattern supports our reasoning that the shorter the time allowed to consider information, the more individuals have to rely on heuristics. As a result, the negativity bias will have a larger impact as there is less time to reconsider the initial predominance of negative cues.

Our findings stand in contrast to the idea that individuals arrive at more negative evaluations when they have more processing time, as a consequence of automatic vigilance bringing negative cues into awareness (Pratto and John 1991). Although automatic vigilance may indeed do this, it does not augment the predictions' degree of negativity. According to category diagnosticity theory, negative cues tend to be more diagnostic compared to positive cues (although there are domains that serve as exceptions, see Skowronski and Carlston 1989). However, the theory does not stipulate whether this leads to more or less negative judgements under conditions of information processing constraint 
or abundance. Our research clarifies that shorter assessments lead to more negative judgements, which represents an initial contribution of this study.

Second, our studies show that longer investigative efforts do not add to predictive accuracy compared to judgements based on short assessments. A classic trade-off noted by decision theorists is that decision accuracy is inversely related to decision speed (Bogacz et al. 2010; Wickelgren 1977). The current study shows that this does not apply when estimating whether a crowdfunding campaign will be successful: predictions were found to be equally accurate regardless of whether participants were given limited or ample time to study a crowdfunding website. Thus, a second contribution of our study is that it adds to the weight of the evidence that system 2 does not necessarily outperform system 1 in evaluation and judgement tasks (Kahneman and Klein 2009). According to Dane and Pratt (2007), two broad sets of factors influence the accuracy of fast judgements: task characteristics and domain knowledge. As a crowdfunding campaign contains a variety of information, and as the crowd consists of (mostly) non-experts, predicting the success of a crowdfunding campaign is a difficult task, as a wide variety of factors will affect its eventual success. Yet, even given these complexities, our study shows that taking more time to process information does not lead to better predictions. The fact that the predictions in the short time condition were more negative but not more accurate shows that these judgments are indeed negatively biased.

Our research also reveals whether people are able to predict, above chance level, the success of crowdfunding campaigns from first impressions, and to compare the accuracy of decisions when using more versus less time. We show that people are able, above chance levels, to accurately judge campaign success in a very brief time frame and based on limited information. These findings are in line with studies using thin-slice methodologies that have reported on the accuracy of immediate judgements (Ambady and Rosenthal 1992; Ambady et al. 2006). At the same time, the correct prediction rates show further room for improvement.

\subsection{Implications for Practice}

Organizations and people who want to be funded by the crowd (called creators here) compete with a vast number of other campaigns (as well as users' other spending goals) for attention and funding. Given the relatively small individual monetary amounts involved in reward-based crowdfunding, many funders may come to a decision without spending much time and effort on processing information. Our study suggests that funders are correct to do so, as their judgements based on short assessments are just as accurate as those based on more lengthy investigations, which are more positive but not more accurate. Thus, founders would be wise to focus their energy on making a good first impression on the crowd, for example by making use of a pitch video and displaying vivid information on the project page (Gierczak and Nitze 2015). Their scarce resources may be best spent on making good first impressions in order to avoid negativity bias. Before publicly posting a campaign, asking a small group of individuals to assess the campaign, while providing them with little time to form their judgement, can be a cost-effective way to obtain information about their first impressions, and thus about the campaign's chance of success. After repairing the negative cues that occur, further resources can be devoted to providing information that turns the initially more negative assessments into positive ones. This information is also of use for crowdfunding platforms and consultants, as they can provide it to seekers of crowdfunding as a service.

\subsection{Limitations and Future Research}

This study comes with a number of limitations. First, our research focused on the initial impressions of campaigns that were depicted as if they had just been launched, leaving comments and updates out. In reality, the number of updates and comments on a crowdfunding project page correlates with the chances of campaign success (Block et al. 2018b; Colombo et al. 2015). People who have funded the campaign are allowed to make comments, and founders provide updates about campaign success. Subsequently, the crowd uses this information, together with information on the current progression 
towards the monetary goal and the number of people who have already invested, as a means of gathering social proof, i.e., looking at others for verification of one's thoughts or actions. Thus, founders should encourage their networks to become early contributors in order to attract later investors.

Second, in our study, judgements in the long condition were found to be more positive than those in the short condition, although they were not more accurate. The question is whether this result also holds if confirmation bias-that is, the search for cues to confirm these initial impressions-is allowed to operate (Oswald and Grosjean 2004). Future research can test this by conducting an additional experiment, in which participants are shown a campaign for a short amount of time, make an estimate, then study the same campaign for longer, and are again asked to make an estimate. In yet another variation of our design, the influence of so-called unconscious thought could also be measured. Dijksterhuis and Aarts (2003) and Dijksterhuis and Nordgren (2006) found evidence that when participants are temporarily distracted from tasks that are relatively complex and that need to be performed relatively quickly, they perform better compared to those who either have hardly any time to process information, or who have ample time to process information, but are not distracted (but see Nieuwenstein et al. (2015) for counter evidence). The unconscious thought advantage hypothesis can be tested by having participants either briefly or extensively study crowdfunding campaigns, be distracted for some time, and then form predictions of crowdfunding success. An obvious limitation of our research is that our studies were limited to reward-based crowdfunding, so both suggestions above can also be tested in donation, loan and equity crowdfunding.

Third, in study 1, the experience of the participants apparently did not translate into an increased ability to predict campaign success. Their experience may not have been relevant to the cases under consideration; it is also possible that merely having experience in crowdfunding does not translate into increased predictive ability because there is no direct feedback loop supporting learning. Dane and Pratt (2007) suggested that experts should have more accurate initial impressions in relatively unstructured situations-our study suggests that experience has not made our participants experts. In this regard, future research could aim to detect people who are highly capable of predicting crowdfunding campaign success, and to theorize what makes them able to do so. This is relevant to those who want to provide training to people who wish to finance their projects using crowdfunding, as such a study would reveal the decision-making processes and rules of experts (Tetlock and Gardner 2015). Such studies could furthermore produce algorithms capable of predicting crowdfunding success, thereby adding, for example, to the machine-learning-based work of Greenberg et al. (2013).

Fourth, study 1 had a limited sample size. Although the data analysis was performed correctly, working with a larger group of participants could have led to different results. Fifth, the sample of study 2 contained only third-year Bachelor students of a Dutch university. Given this specific sample, caution is advised with generalization. It is recommended to perform similar research among other groups of people as well.

\subsection{Conclusions}

Crowdfunding has taken the world by storm and offers new and exciting possibilities for both entrepreneurial organizations and individuals and those who wish to take part in their endeavors as funders. Our study contributes by testing the effects of assessment time on the positivity and accuracy of assessments and adds to the growing body of crowdfunding literature.

We have learned that negative cues catch the eye of people quickly; a characteristic of human behavior that, like most—or maybe all—features of human and other animal behavior, seems to be shaped by evolution. A strong preference for immediately processing potentially dangerous information before everything else, helps species to survive by steering clear from harmful events. However, when more time is spent on assessing a situation, this negativity or negativity bias appears to decrease. This is intriguing, as a phenomenon known as the confirmation bias exists as well. The confirmation bias states that people form opinions quickly, then look for cues in additional information to confirm this opinion, thereby effectively ignoring possibly important information that challenges their initial 
response, or even proves it wrong. The hierarchy and interplay of cognition biases is an interesting subject that would benefit from more attention in various academic fields, among them the study of crowdfunding.

Author Contributions: Conceptualization, E.S. and M.v.G.; Data curation, E.S.; Formal analysis, E.S.; Investigation, E.S.; Methodology, E.S. and M.v.G.; Project administration, E.S.; Supervision, E.v.B., M.v.G. and E.M.; Validation, E.S.; Writing—original draft, E.S.; Writing—review \& editing, E.v.B., M.v.G. and E.M. All authors have read and agreed to the published version of the manuscript.

Funding: This research received no external funding.

Conflicts of Interest: The authors declare no conflict of interest.

\section{References}

Allison, Thomas H., Blakley C. Davis, Jeremy C. Short, and Justin W. Webb. 2015. Crowdfunding in a prosocial microlending environment: Examining the role of intrinsic versus extrinsic cues. Entrepreneurship Theory and Practice 39: 53-73. [CrossRef]

Ambady, Nalini. 2010. The perils of pondering: Intuition and thin slice judgments. Psychological Inquiry 21: 271-78. [CrossRef]

Ambady, Nalini, and Robert Rosenthal. 1992. Thin slices of expressive behavior as predictors of interpersonal consequences: A meta-analysis. Psychological Bulletin 111: 256-74. [CrossRef]

Ambady, Nalini, Mary A. Krabbenhoft, and Daniel Hogan. 2006. The 30-s sale: Using thin-slice judgments to evaluate sales effectiveness. Journal of Consumer Psychology 16: 4-13. [CrossRef]

Ante, Lennart, Philipp Sandner, and Ingo Fiedler. 2018. Blockchain-based ICOs: Pure hype or the dawn of a new era of startup financing? Journal of Risk and Financial Management 11: 80. [CrossRef]

Bargh, John A., and Tanya L. Chartrand. 1999. The unbearable automaticity of being. American Psychologist 54: 462-79. [CrossRef]

Baumeister, Roy F., Ellen Bratslavsky, Catrin Finkenauer, and Kathleen D. Vohs. 2001. Bad is stronger than good. Review of General Psychology 5: 323-70. [CrossRef]

Bernardino, Susana, and J. Freitas Santos. 2020. Crowdfunding: An explanatory study on knowledge, benefits and barriers perceived by young potential entrepreneurs. Journal of Risk and Financial Management 13: 81. [CrossRef]

Block, Joern H., Massimo G. Colombo, Douglas J. Cumming, and Silvio Vismara. 2018a. New players in entrepreneurial finance and why they are there. Small Business Economics 50: 239-50. [CrossRef]

Block, Jörn, Lars Hornuf, and Alexander Moritz. 2018b. Which updates during an equity crowdfunding campaign increase crowd participation? Small Business Economics 50: 3-27. [CrossRef]

Bogacz, Rafal, Eric J. Wagenmakers, Birte U. Forstmann, and Sander Nieuwenhuis. 2010. The neural basis of the speed-accuracy tradeoff. Trends in Neurosciences 33: 10-16. [CrossRef] [PubMed]

Bruton, Garry, Susanna Khavul, Donald Siegel, and Mike Wright. 2015. New financial alternatives in seeding entrepreneurship: Microfinance, crowdfunding, and peer-to-peer innovations. Entrepreneurship Theory and Practice 39: 9-26. [CrossRef]

Chaiken, Shelly, and Yaacov Trope, eds. 1999. Dual-Process Theories in Social Psychology. New York: Guilford Press.

Cholakova, Magdalena, and Bart Clarysse. 2015. Does the possibility to make equity investments in crowdfunding projects crowd out reward-based investments? Entrepreneurship Theory and Practice 39: 145-7. [CrossRef]

Colombo, Massimo G., Chiara Franzoni, and Cristina Rossi-Lamastra. 2015. Internal social capital and the attraction of early contributions in crowdfunding. Entrepreneurship Theory and Practice 39: 75-100. [CrossRef]

Dane, Erik, and Michael G. Pratt. 2007. Exploring intuition and its role in managerial decision making. Academy of Management Review 32: 33-54. [CrossRef]

Dijksterhuis, Ap, and Henk Aarts. 2003. On wildebeests and humans: The preferential detection of negative stimuli. Psychological Science 14: 14-18. [CrossRef]

Dijksterhuis, Ap, and Loran F. Nordgren. 2006. A theory of unconscious thought. Perspectives on Psychological Science 1: 95-109. [CrossRef]

Fennis, Bob M., and Wolfgang Stroebe. 2010. The Psychology of Advertising. New York: Psychology Press. 
Frese, Michael. 2007. The psychological actions and entrepreneurial success: An action theory approach. In The Psychology of Entrepreneurship. Edited by J. Robert Baum, Michael Frese and Robert A. Baron. Mahwah: Lawrence Erlbaum, pp. 151-88.

Genevsky, Alexander, Carolyn Yoon, and Brian Knutson. 2017. When brain beats behavior: Neuroforecasting crowdfunding outcomes. Journal of Neuroscience 37: 8625-34. [CrossRef]

Gerber, Elizabeth M., Julie S. Hui, and Pei-Y. Kuo. 2012. Crowdfunding: Why people are motivated to post and fund projects on crowdfunding platforms. Paper presented at International Workshop on Design, Influence, and Social Technologies: Techniques, Impacts and Ethics, Evanston, IL, USA, February 11; Evanston: Northwestern University Evanston.

Gierczak, Michael Marcin, and Hans Kristian Nitze. 2015. Shine Bright Like a Diamond-Exploring the Effects of Online-Product Presentation on Backing Behavior in Reward-Based Crowdfunding. ECIS 2015 Research-in-Progress Papers. Paper 59. Available online: http://aisel.aisnet.org/ecis2015_rip/59 (accessed on 5 November 2018).

Gigerenzer, Gierczak, and Wolfgang Gaissmaier. 2011. Heuristic decision making. Annual Review of Psychology 62: 451-82. [CrossRef]

Greenberg, Michael D., Bryan Pardo, Karthic Hariharan, and Elizabeth Gerber. 2013. Crowdfunding support tools: Predicting success and failure. In CHI'13 Extended Abstracts on Human Factors in Computing Systems. New York: ACM, pp. 1815-20. Available online: http://dl.acm.org/citation.cfm?id=2468682 (accessed on 10 November 2018).

Hansen, Christine H., and Ranald D. Hansen. 1988. Finding the face in the crowd: An anger superiority effect. Journal of Personality and Social Psychology 54: 917-24. [CrossRef]

Hemer, Joachim. 2011. A Snapshot on Crowdfunding (No. R2/2011). Working Papers Firms and Region. Karlsruhe: Fraunhofer ISI.

Ito, Tiffany A., Jeff T. Larsen, N. Kyle Smith, and John T. Cacioppo. 1998. Negative information weighs more heavily on the brain: The negativity bias in evaluative categorizations. Journal of Personality and Social Psychology 75: 887-900. [CrossRef] [PubMed]

Kahneman, Daniel. 2011. Thinking, Fast and Slow. New York: Farrar, Straus and Giroux, vol. 1.

Kahneman, Daniel, and Gary Klein. 2009. Conditions for intuitive expertise: A failure to disagree. American Psychologist 64: 515-26. [CrossRef] [PubMed]

Kahneman, Daniel, and Amos Tversky. 1979. Prospect theory: An analysis of decisions under risk. Econometrica 47: 263-91. [CrossRef]

Kickstarter Stats. 2015. Available online: https://www.kickstarter.com/help/stats (accessed on 1 October 2015).

Kim, Heejun, and Daniel R. Fesenmaier. 2008. Persuasive design of destination web sites: An analysis of first impression. Journal of Travel Research 47: 3-13. [CrossRef]

Kuppuswammy, Venkat, and Kathy Roth. 2016. Research on the Current State of Crowdfunding: The Effect of Crowdfunding Performance and Outside Capital; Tampa: US Small Business Administration Office of Advocacy.

Ley, Andy, and Scott Weaven. 2011. Exploring agency dynamics of crowdfunding in start-up capital financing. Academy of Entrepreneurship Journal 17: 85.

Lindgaard, Gitte, Gary Fernandes, Cathy Dudek, and Judith Brown. 2006. Attention web designers: You have 50 milliseconds to make a good first impression! Behaviour E Information Technology 25: 115-26.

Miglo, Anton. 2020. Crowdfunding in a competitive environment. Journal of Risk and Financial Management 13: 39. [CrossRef]

Miller, C. Chet, and Peter Bamberger. 2016. Exploring emergent and poorly understood phenomena in the strangest of places: The footprint of discovery in replications, meta-analyses, and null findings. Academy of Management Discovery 2: 313-19. [CrossRef]

Mollick, Ethan. 2014. The dynamics of crowdfunding: An exploratory study. Journal of Business Venturing 29: 1-16. [CrossRef]

Mukherjee, Kanchan. 2010. A dual system model of preferences under risk. Psychological Review 117: $243-55$. [CrossRef]

Mynatt, Clifford R., Mynatt E. Doherty, and Ryan D. Tweney. 1977. Confirmation bias in a simulated research environment: An experimental study of scientific inference. The Quarterly Journal of Experimental Psychology 29: 85-95. [CrossRef] 
Neuberg, Steven L. 1989. The goal of forming accurate impressions during social interactions: Attenuating the impact of negative expectancies. Journal of Personality and Social Psychology 56: 374-86. [CrossRef]

Nickerson, Raymond S. 1998. Confirmation bias: A ubiquitous phenomenon in many guises. Review of General Psychology 2: 175-220. [CrossRef]

Nieuwenstein, Mark R., Tjardie Wierenga, Richard D. Morey, Jelte M. Wicherts, Tesse N. Blom, Eric J. Wagenmakers, and Hedderik van Rijn. 2015. On making the right choice: A meta-analysis and large-scale replication attempt of the unconscious thought advantage. Judgment and Decision Making 10: 1-17.

Oehman, Arna, Daniel Lundqvist, and Francisco Esteves. 2001. The face in the crowd revisited: A threat advantage with schematic stimuli. Journal of Personality and Social Psychology 80: 381-96. [CrossRef] [PubMed]

Oswald, Margit E., and Stefan Grosjean. 2004. Confirmation bias. In Cognitive Illusions: A Handbook on Fallacies and Biases in Thinking, Judgement and Memory. Edited by Rüdiger F. Pohl. Hove: Psychology Press, pp. 79-96.

Park, Sangwon, and Juan L. Nicolau. 2015. Asymmetric effects of online consumer reviews. Annals of Tourism Research 50: 67-83. [CrossRef]

Peracchio, Laura A., and David Luna. 2006. The role of thin-slice judgments in consumer psychology. Journal of Consumer Psychology 16: 25-32. [CrossRef]

Pratto, Felicia, and Oliver P. John. 1991. Automatic vigilance: The attention-grabbing power of negative social information. Journal of Personality and Social of Psychology 61: 380-91. [CrossRef]

Rabin, Matthew, and Joel L. Schrag. 1999. First impressions matter: A model of confirmatory bias. The Quarterly Journal of Economics 114: 37-82. [CrossRef]

Rozin, Paul, and Edward B. Royzman. 2001. Negativity bias, negativity dominance, and contagion. Personality and Social Psychology Review 5: 296-320. [CrossRef]

Schwienbacher, Armin. 2018. Entrepreneurial risk-taking in crowdfunding campaigns. Small Business Economics 51: 843-59. [CrossRef]

Shah, Anuj K., and Daniel M. Oppenheimer. 2008. Heuristics made easy: An effort-reduction framework. Psychological Bulletin 134: 207-22. [CrossRef] [PubMed]

Simon, Herbert A. 1957. Models of Man. New York: John Wiley.

Simon, Herbert A. 1972. Theories of bounded rationality. Decision and Organization 1: 161-76.

Skowronski, John J., and Donal E. Carlston. 1989. Negativity and extremity biases in impression formation: A review of explanations. Psychological Bulletin 105: 131-42. [CrossRef]

Stanovich, Keith E., and Richard F. West. 2000. Individual differences in reasoning: Implications for the rationality debate? Behavioral and Brain Sciences 23: 645-65. [CrossRef] [PubMed]

Tetlock, Philip E., and Dan Gardner. 2015. Superforecasting: The Art and Science of Prediction. New York: Random House.

Ullah, Saif, and Yulin Zhou. 2020. Gender, anonymity and team: What determines crowdfunding success on Kickstarter. Journal of Risk and Financial Management 13: 80. [CrossRef]

Wickelgren, Wayne A. 1977. Speed-accuracy tradeoff and information processing dynamics. Acta Psychologica 41: 67-85. [CrossRef]

Wilson, Timothy D., and Jonathan W. Schooler. 1991. Thinking too much: Introspection can reduce the quality of preferences and decisions. Journal of Personality and Social Psychology 60: 181-92. [CrossRef]

Publisher's Note: MDPI stays neutral with regard to jurisdictional claims in published maps and institutional affiliations.

(C) 2020 by the authors. Licensee MDPI, Basel, Switzerland. This article is an open access article distributed under the terms and conditions of the Creative Commons Attribution (CC BY) license (http://creativecommons.org/licenses/by/4.0/). 